\title{
Studies on Underwater Sounds Produced by Japanese Horse Mackerel Trachurus japonicus in Net Pens at Culture Grounds in Innermost Kagoshima Bay
}

\author{
Frangky Erens Kaparang, ${ }^{* 1, \dagger}$ Yasuhisa Matsuno, ${ }^{* 2}$ \\ Yuichi Yamanaka, ${ }^{* 2}$ and Shigeru Fujieda*2 \\ ${ }^{*}$ The United Graduate School of Agricultural Science, Kagoshima University, \\ Korimoto, Kagoshima 890-0065, Japan \\ ${ }^{*_{2}}$ Faculty of Fisheries, Kagoshima University, Shimoarata, \\ Kagoshima 890-0056, Japan
}

(Received October 12, 1998)

\begin{abstract}
The differences between swimming and feeding activity of recorded underwater sound in summer and winter produced by japanese horse mackerel in a net pen were analyzed using the one-third octave band method. The small and big-sized fish show the same curve patterns under swimming and bait-eating activity in summer, but in the term of the maximum and minimum level frequencies, it seems slightly different. The swimming sound curve pattern in summer was same as in winter, but there were some different patterns in bait-eating sound. The two respective records obtained simultaneously on the inside and outside of net pen when swimming activity were same in regard to the pattern and sound level, but the records when bait-eating activity were different.
\end{abstract}

Key words: swimming sound, bait-eating sound, japanese horse mackerel, one-third octave band analysis

It is well known that many marine fishes produce sounds when moving about in the water column. The spectrum of sound produced by marine animal is characteristic of the species, so these sounds can be used for detecting, attracting or repelling fish schools. ${ }^{1)} \mathrm{A}$ device for gathering fish schools by using underwater acoustical equipment was conceived with the idea that if fish schools could be lured to a location and driven into a fish net by emitting an effective sound, fishing efficiency could be increased. ${ }^{2)}$

Some series of experiments report on underwater sound produced by fishes in net pens at the culture ground have been published previously. ${ }^{3-5)}$ In the previous study, the different sound of yellowtail and amberjack for swimming and feeding conditions was reported. ${ }^{6}$ However, the underwater sound of japanese horse mackerel has not been examined thoroughly.

The present study was undertaken to obtain more information on underwater sound produced by japanese horse mackerel (named "ma-aji" in Japanese). The purposes of this paper are to study characteristics of underwater sound produced by japanese horse mackerel; to examine the relationship between swimming sound and feeding sound; to compare sounds in the summer with those in the winter and finally, to contrast the recorded sound simultaneously by two hydrophones located inside and outside the net pen.

In the Kagoshima waters, japanese horse mackerel is one of main target fishes of small size purse-seine fisheries. This data could be used for identification, detecting, gathering and luring fish schools.

\section{Materials and Methods}

\section{Research Subject}

The subjects of this research were japanese horse mackerel Trachurus japonicus in schooling during the swimming and feeding activities. The average size and weight of the fish were shown in Table 1. The examined fishes were divided into two size categories, i.e., small size (weight 90$120 \mathrm{~g}$; length $20-23 \mathrm{~cm}$ ) and big size (weight $280-320 \mathrm{~g}$; length $28-30 \mathrm{~cm}$ ).

\section{Research Field Condition and Net Pen}

The Kurokami culture ground is situated in the eastern coastal waters of Sakurajima, Kagoshima Prefecture (Fig. 1). The net pens were laying around 0.1 nautical mile offshore with of depth about $50 \mathrm{~m}$. The cubical net pen with size $8 \mathrm{~m}$ in length, $8 \mathrm{~m}$ in width and $8 \mathrm{~m}$ in depth is made of galvanized iron pipes and covered by galvanized iron netting panels or synthetic fiber netting that are buoyed up by foaming floats.

Table 1. Average size and amount of examined fish

\begin{tabular}{lcccc}
\hline \hline \multirow{2}{*}{ Size category } & \multirow{2}{*}{$\begin{array}{c}\text { Average } \\
\text { weight }\end{array}$} & $\begin{array}{c}\text { Average } \\
\text { length }\end{array}$ & \multicolumn{2}{c}{ Number of fish* } \\
\cline { 4 - 5 } & & & Summer & Winter \\
\hline Small size & $90 \mathrm{~g}-120 \mathrm{~g}$ & $20 \mathrm{~cm}-23 \mathrm{~cm}$ & 20000 & - \\
Big size & $280 \mathrm{~g}-320 \mathrm{~g}$ & $28 \mathrm{~cm}-30 \mathrm{~cm}$ & 10000 & 7000 \\
\hline
\end{tabular}

*Estimated value.

\footnotetext{
${ }^{\dagger}$ Corresponding author: Faculty of Fisheries, Sam Ratulangi University, Manado 95115, North Sulawesi, Indonesia.
} 


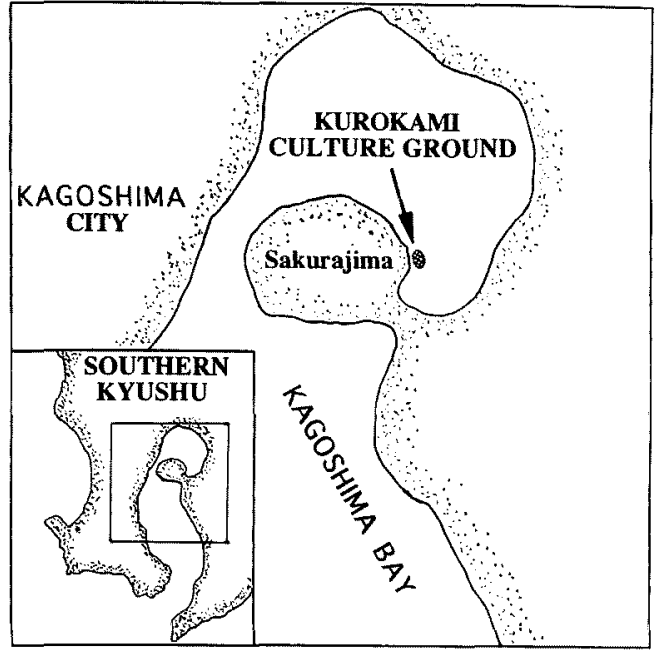

Fig. 1. Location of Kurokami culture ground.

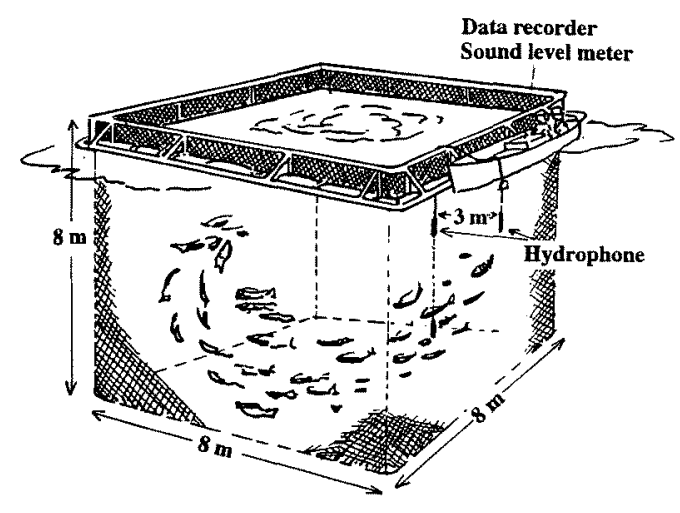

Fig. 2. Recording method in a net pen.

At the time underwater sound investigation was carried out, the weather and sea conditions were as follows: clearcloudy, none wind, calm sea, water temperate of $26.8^{\circ} \mathrm{C}$ (in summer) and $16.3^{\circ} \mathrm{C}$ (in winter).

Bait for fish were moisture pellets with a diameter of about $1 \mathrm{~cm}$.

\section{Data Collecting Procedure}

The underwater sound was received with a hydrophone (OKI SW 1020) which connected with underwater levelmeter (OKI ST 1020) and recorded by PCM data recorder (TEAC RD-101T). A hydrophone was hung at the depth of $3 \mathrm{~m}$ (when bait-eating) and $6 \mathrm{~m}$ (when swimming) on the inside of net pen in the summer. However, in the winter, two hydrophones were hung on the inside and outside of net pen separately, by putting 3 meters of space between them (Fig. 2).

The underwater sound was being recorded when there was no noise from boat or other noise source. The bait was spread by hand during bait-eating activity. The underwater levelmeter cut off frequency of the low pass filter was adjusted to $10 \mathrm{kHz}$ and that of the high pass filter was adjusted to $10 \mathrm{~Hz}$. The data recorder also recorded some use- ful information related to the experiment.

\section{Data Analysis Procedure}

Data recorded in the net pen were examined by the onethird octave band method. In the one-third octave band analysis method, the sound and vibration signal analyzer (RION SA74A) was used. The average of five pieces data (one datum length; continuous 1 minute 7 second) was used.

Center frequencies of one-third octave band filters were from $16 \mathrm{~Hz}-8 \mathrm{kHz}$, with the minimum cut off frequency of $14 \mathrm{~Hz}$ and the maximum cut off frequency of $9 \mathrm{kHz}$. The reference sound pressure level was $1 \mu \mathrm{Pa}$. The resultant frequency characteristics were compared, based on the respective sizes, activities of the schooled fish, season (only summer and winter) and position of where hydrophone was placed (inside and outside the net pen).

\section{Results and Discussion}

One-third octave band analysis graph of japanese horse mackerel's underwater sound showed some curve pattern with three separated certain frequency bandwidths such as in the low frequency bandwidths, in the middle frequency bandwidths where the hollow curve that steeps decrease and becomes concave, and in the high frequency bandwidths.

\section{Swimming Sound}

Swimming sound of japanese horse mackerel in summer showed same pattern in small-sized ones and big-sized specimens (Fig. 3). The low frequency bandwidth of both sizes appeared below $200 \mathrm{~Hz}$. Small-sized fish curve in low frequency bandwidth have high level from $31.5 \mathrm{~Hz}$, but big-sized ones from $40 \mathrm{~Hz}$. The concave bandwidth appeared in frequency $200 \mathrm{~Hz}-1.25 \mathrm{kHz}$ and has minimum level at $500 \mathrm{~Hz}$ for small-sized fish and at $400 \mathrm{~Hz}$ for bigsized ones. The minimum level frequency was higher for small-sized fish, and was lower for the big-sized ones. In the high frequency bandwidth, both sizes showed that the sound levels increase when frequencies become higher.

The maximum level frequency of small-sized japanese horse mackerel in summer was $8 \mathrm{kHz}$, but big-sized ones was $6.3 \mathrm{kHz}$. The maximum level frequency of small-sized fish was a little higher than big-sized ones. It presumed that the small-sized fish and the big-sized ones generally produced same type of frequency under their swimming activities.

In comparing with small-sized $(70 \mathrm{~g})$ of yellowtails swimming sound pattern, ${ }^{6}$ both sized japanese horse mackerel swimming sounds pattern have differences with yellowtail's pattern and also with red sea bream's sound under swimming activity, ${ }^{5}$ which is horse mackerel's swimming sound pattern showed upward curve in high bandwidth frequency. Other species reported that the swimming sound of $1.5 \mathrm{~kg}$ yellowtails produced the maximum level of 64 $\mathrm{Hz} .{ }^{3)}$ which this examined species was bigger than present object.

Swimming sound of big-sized ones in winter showed difference pattern with in the summer (Fig. 4). The concave curve in middle frequency bandwidth of swimming sound in winter was not clearly appeared in about $125 \mathrm{~Hz}-$ 


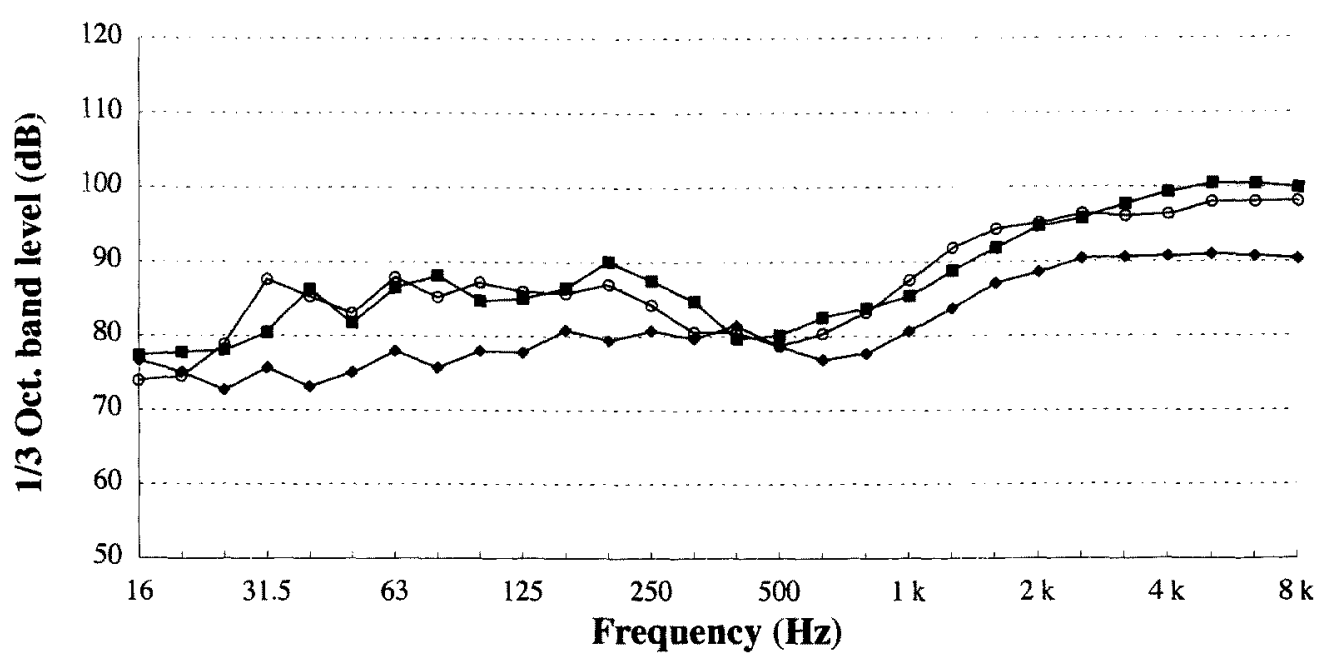

Fig. 3. One-third octave band analyses of swimming sound in summer. - Small size; - - Big size; - - Ambient noises.

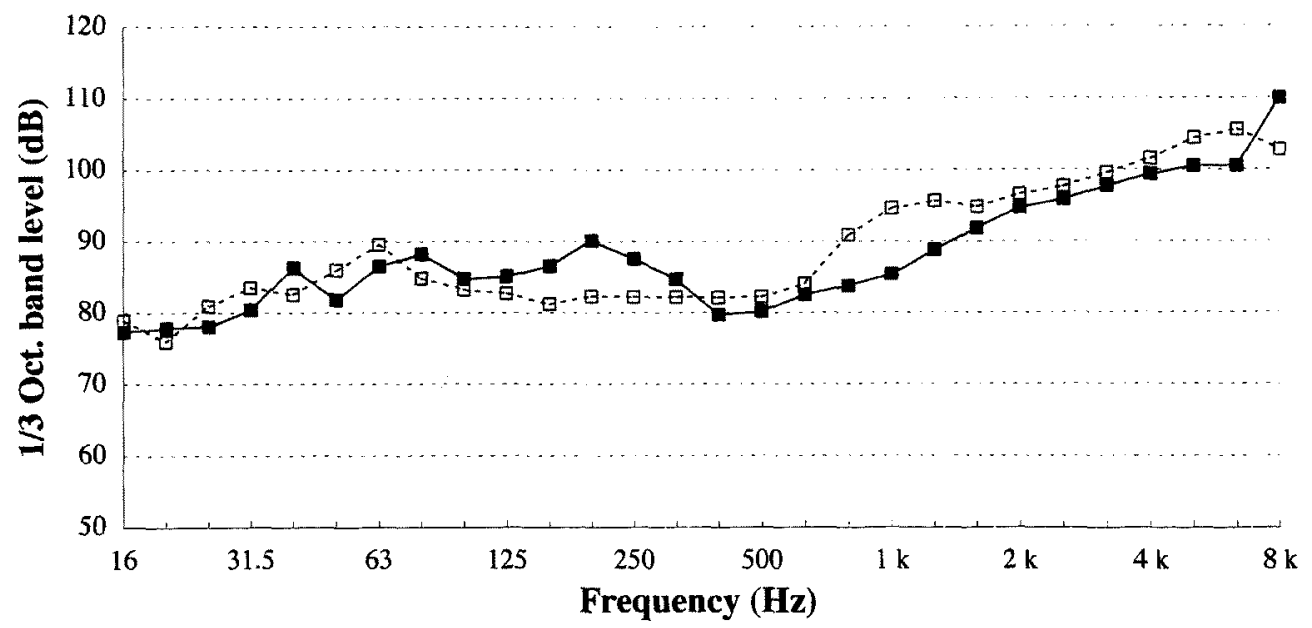

Fig. 4. One-third octave band analyses of swimming sound of big size fish. - - Summer (inside); - $-\Xi--$ Winter (inside).

$200 \mathrm{~Hz}$. Apparently, curve of swimming sound in winter has flat curve from $100 \mathrm{~Hz}$ until $500 \mathrm{~Hz}$, but become convex curve in summer. The other way, the winter curve sharply increased in $630 \mathrm{~Hz}$ to $1 \mathrm{kHz}$, but in summer, it was gradually increased until $2 \mathrm{kHz}$.

The maximum level frequency of big-sized fish in winter is at $6.3 \mathrm{kHz}$, also in summer. The minimum level frequency of concave bandwidth of big-sized ones in winter is at $160 \mathrm{~Hz}$, but in summer at $400 \mathrm{~Hz}$. It means that the minimum level frequency under swimming was decreased in winter.

\section{Bait-eating Sound}

The bait-eating sounds of japanese horse mackerel in summer showed the same pattern in both small and big sized fish (Fig. 5). In the low frequency band, the big-sized sound showed a convex curve from $31.5 \mathrm{~Hz}$ to $50 \mathrm{~Hz}$ and on the contrary become concave at small-sized ones. In the middle frequency bandwidth, small-sized fish showed another convex curve from $630 \mathrm{~Hz}$ to $1.25 \mathrm{kHz}$ and just the opposites become concave with large specimens.

The maximum level frequencies of small and big-sized specimens in summer were same at $100 \mathrm{~Hz}$. In the meantime, the minimum level frequencies of middle frequency bandwidth of big and small-sized fish in summer were also same at $315 \mathrm{~Hz}$. It presumed that small and big-sized fish generally produced same type frequency under bait-eating activity.

The bait-eating sound of big-sized fish in winter showed a flat pattern, but in summer it showed curve pattern (Fig. 6). In the low frequency bandwidth, the flat pattern showed an increased level of frequency of $40 \mathrm{~Hz}$.

In comparing with other species reported that the sound curve of small-sized yellowtail (fish weight about $70 \mathrm{~g}$ at Tarumizu culture ground) ${ }^{6}$ and amberjack (fish weight about $3.5 \mathrm{~kg}$ at Higashi Sakurajima culture ground) ${ }^{4)}$ under bait eating, apparently, have same pattern with the present summer bait-eating sound curve pattern result.

According to Matsuno et al., ${ }^{5)}$ the maximum level of amberjack in Akoubaru culture ground (fish weight about 


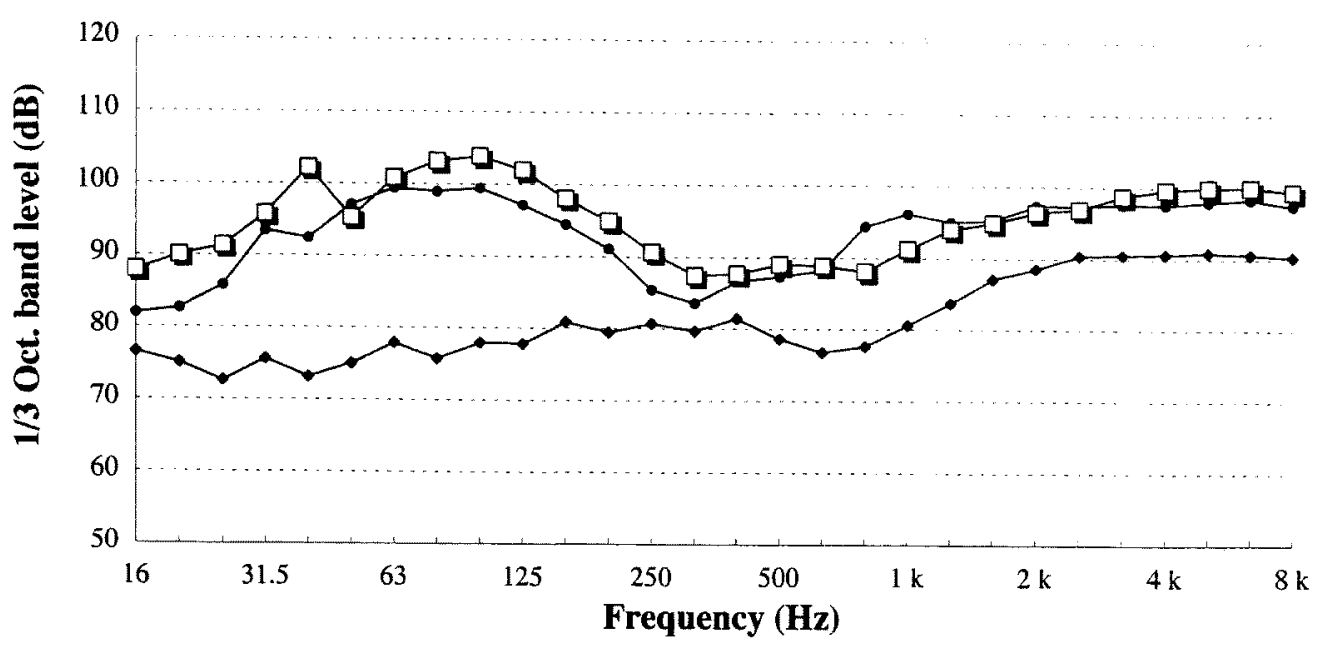

Fig. 5. One-third octave band analyses of bait-eating sound in summer. - - Small size; - - Big size; —- Ambient noises.

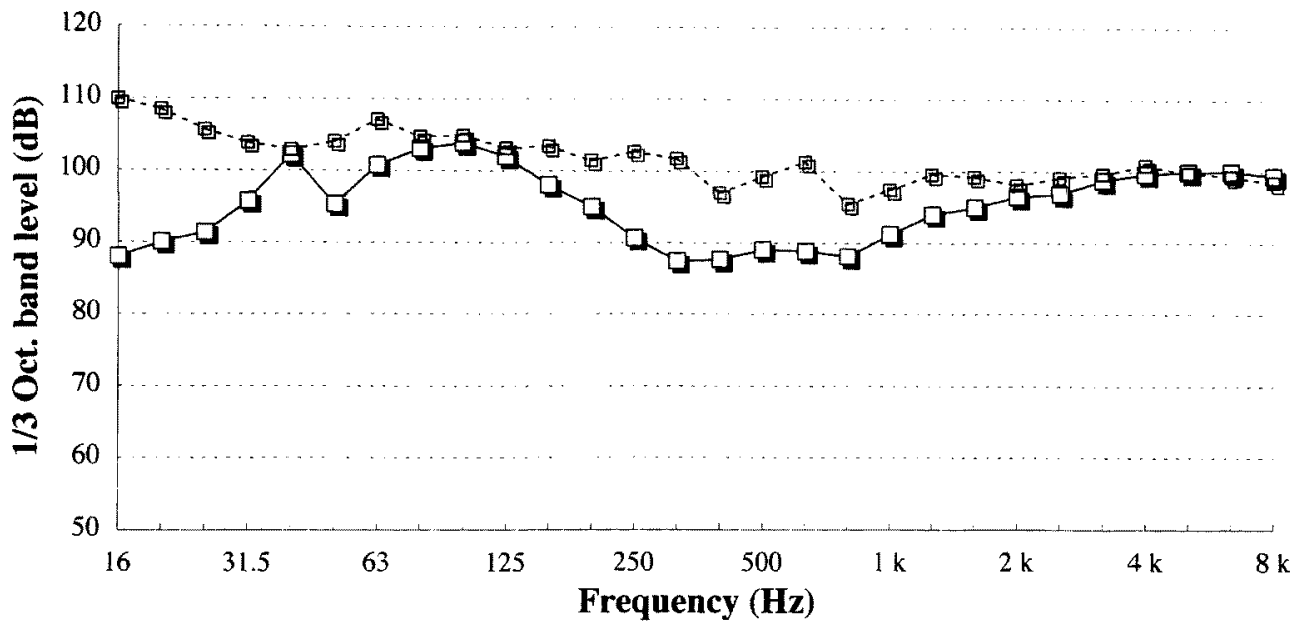

Fig. 6. One-third octave band analyses of bait-eating sound of big size fish,

- - - Summer (inside); - - - - - Winter (inside).

$500 \mathrm{~g}$ ) were $25 \mathrm{~Hz}, 63 \mathrm{~Hz}$ and $6.3 \mathrm{kHz}$ under bait eating activity. which is slightly same with the present result.

\section{Swimming Sound Compare to Bait-eating Sound}

The sound curve pattern of small-sized fish in summer showed same pattern under swimming with under bait-eating activities (Fig. 7). Sound level of bait-eating increased in low and middle frequency bandwidths. In low the frequency bandwidth, the sound level increased from $16 \mathrm{~Hz}$ until $200 \mathrm{~Hz}$. In the middle frequency bandwidth, the sound level was increased from $315 \mathrm{~Hz}$ until $1.25 \mathrm{kHz}$. The $70 \mathrm{~g}$ amberjack's bait-eating sound curve also increased in the low frequency bandwidth in $16 \mathrm{~Hz}-160 \mathrm{~Hz}$ compared to the swimming sound curve. ${ }^{4)}$

The sound curve pattern of big-sized fish in summer also showed the same pattern under swimming during bait-eating activities (Fig. 8). The sound level of bait-eating was increased in low and middle frequency bandwidths. In the low frequency bandwidth, the sound level was significantly increased from $16 \mathrm{~Hz}$ until $200 \mathrm{~Hz}$. In the middle frequency bandwidth, the sound level was increased from

\section{$400 \mathrm{~Hz}$ to $2 \mathrm{kHz}$.}

In the low frequency bandwidth, the represented difference sound level during bait-eating from that during swimming of big-sized fish was bigger than of that small-sized ones. But, in the middle frequency bandwidth, the represented difference sound level during bait-eating from that during swimming of small-size fish was bigger than of big-sized ones. It presumed that big-sized japanese horse mackerel activity during bait-eating produced higher energy than small-sized ones in low frequency bandwidth.

The overall underwater sound levels of bait-eating activity were higher than during swimming activity. This result was similar to other previous researches. ${ }^{3,5,6)}$

The difference overall underwater sound of small-sized fish in summer during both activities was $4.0 \mathrm{~dB}$. The difference of overall underwater sound of big-sized fish in summer during both activities was $4.6 \mathrm{~dB}$. The difference of overall underwater sound of big-sized fish in winter during both activities was $9.3 \mathrm{~dB}$ (hydrophone was hung inside the net pen).

The sound curve pattern of big-sized fish in winter 


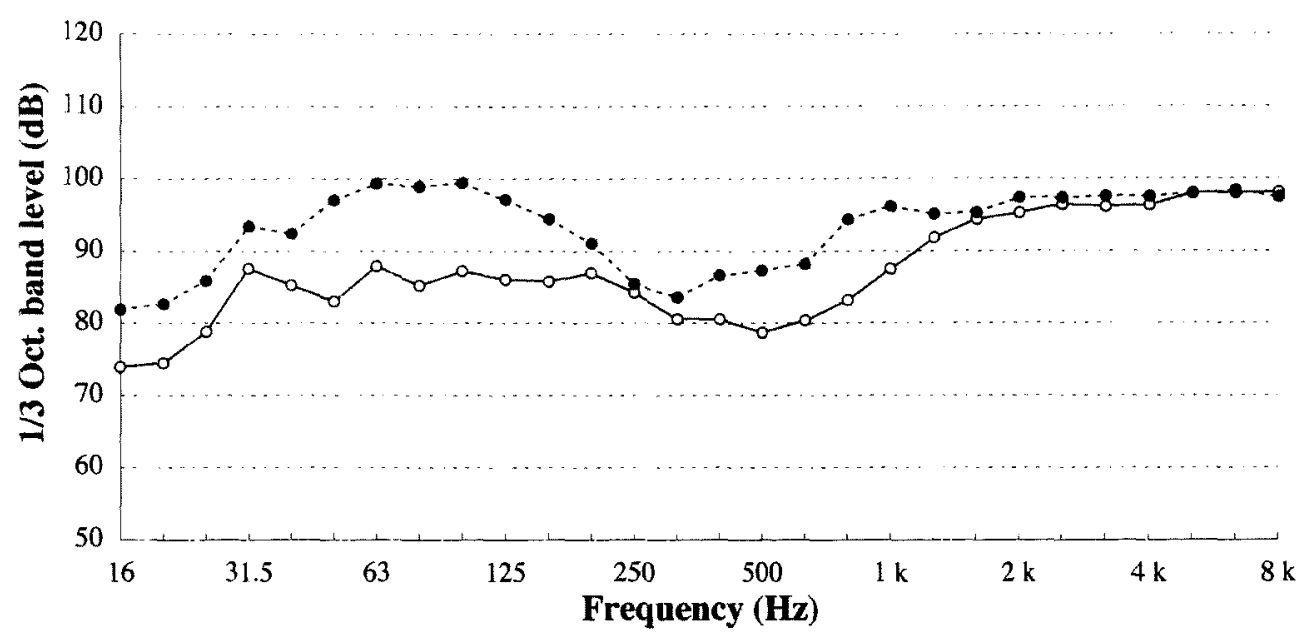

Fig. 7. One-third octave band analyses of underwater sound of small size fish in summer. $-0-$ During swimming; --- During bait-eating.

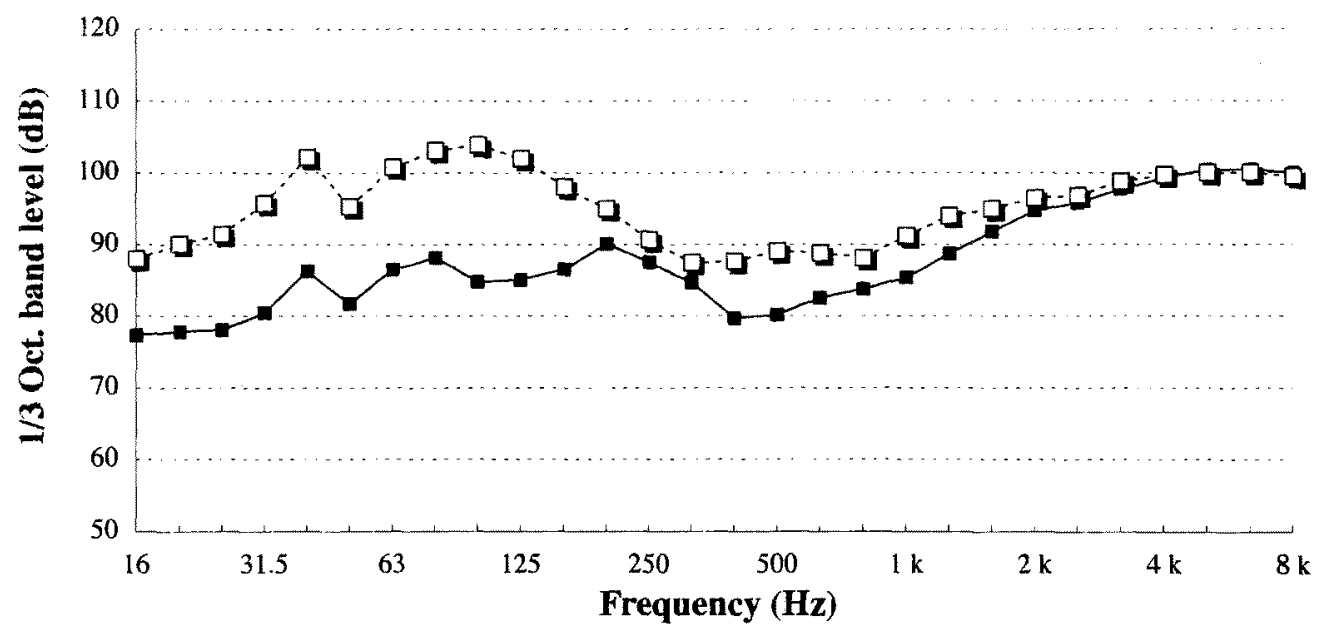

Fig. 8. One-third octave band analyses of underwater sound of big size fish in summer. - - During swimming;-- D-Dring bait-eating.

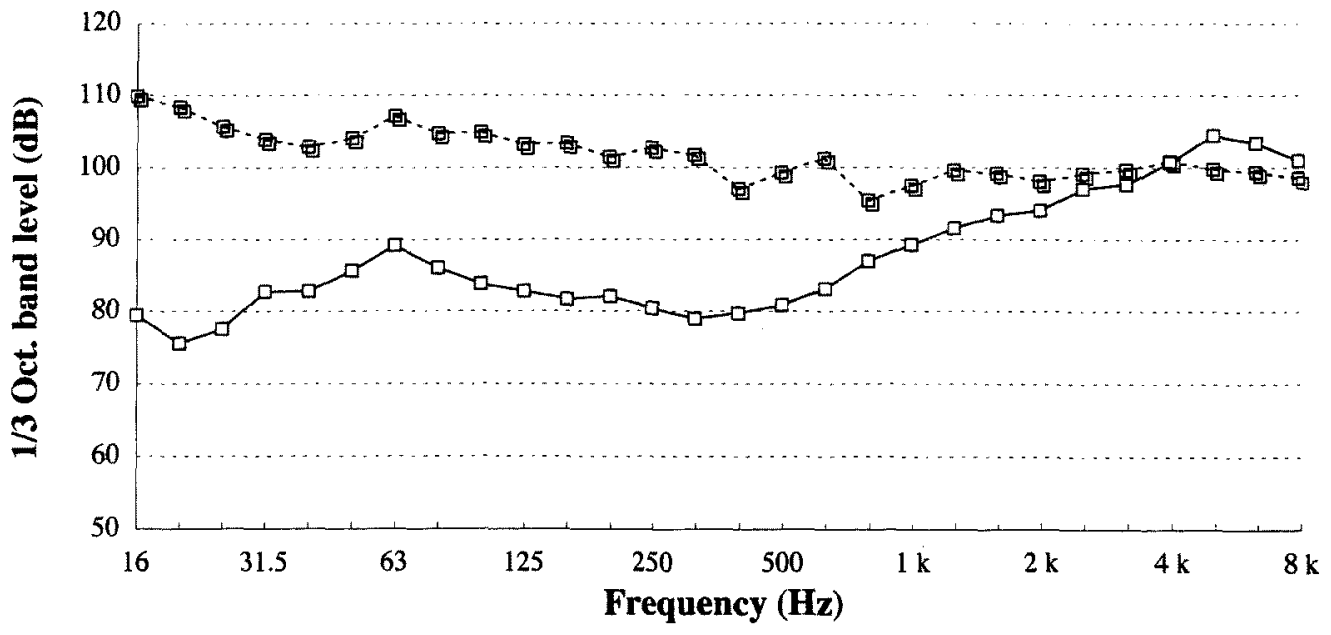

Fig. 9. One-third octave band analyses of underwater sound of big size fish in winter. - - During swimming; - - - - During bait-eating. 


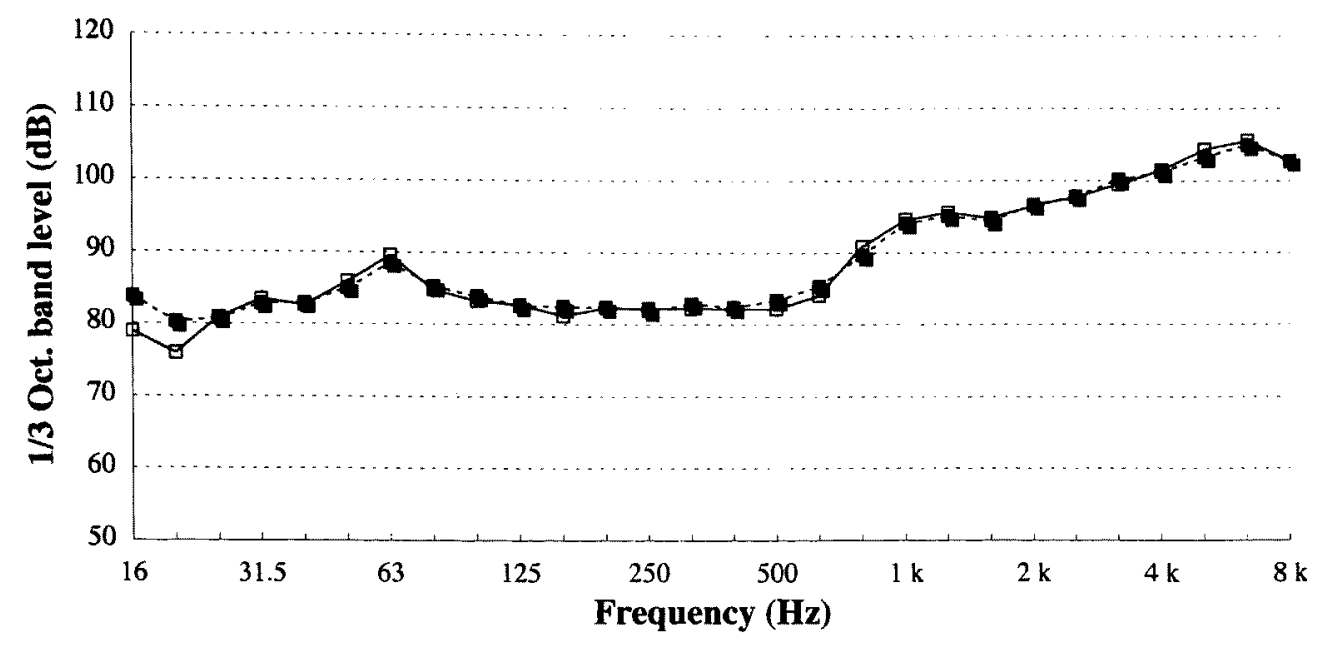

Fig. 10. One-third octave band analyses of swimming sound of big size fish in winter. $\square-$ Inside; - - - Outside.

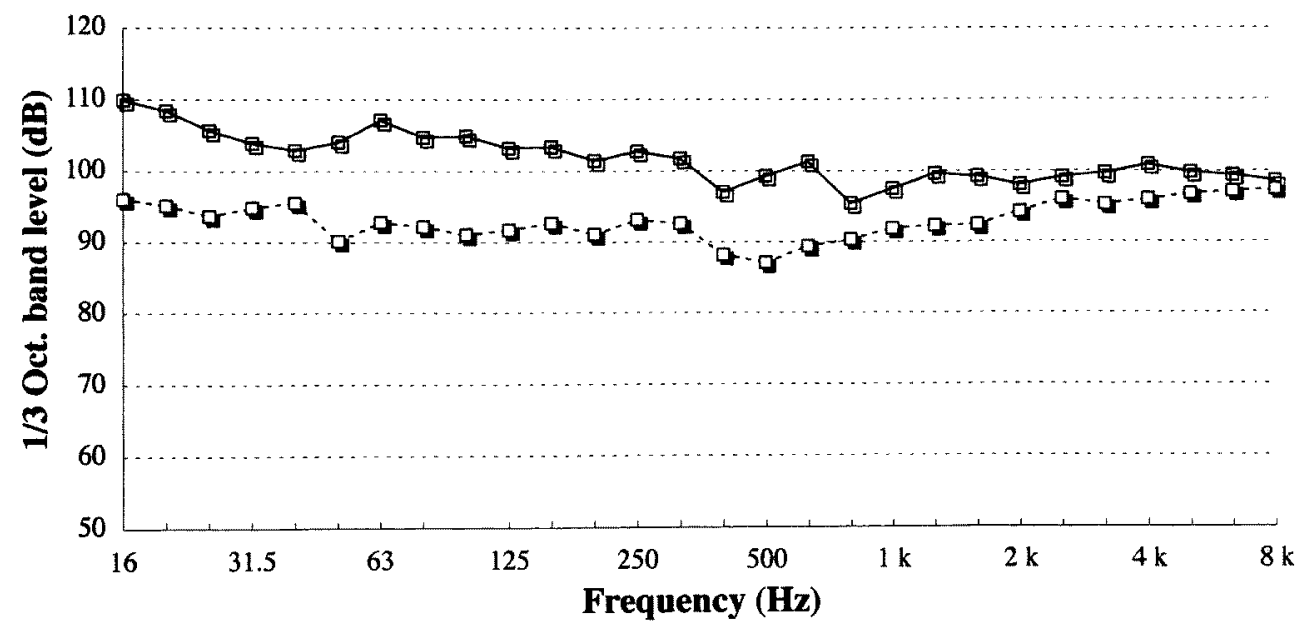

Fig. 11. One-third octave band analyses of bait-eating sound of big size fish in winter. - 7 - Inside; - - - Outside.

showed a different pattern during swimming from that during bait eating activities (Fig. 9). All of sound levels of the bait-eating sound curve are higher than those of swimming activity from low frequency bandwidth until $2 \mathrm{kHz}$ frequencies. The bait eating sound level is greatly different from swimming sound from $16 \mathrm{~Hz}-1 \mathrm{kHz}$. The swimming sound level is slightly higher at $5 \mathrm{kHz}-8 \mathrm{kHz}$. It may be caused by water surface ripples.

The difference in level of both activities of big-sized fish sound in winter was larger than big-sized fish sound in summer, if bait-eating activity was the same action in both seasons. It is presumed that fishes are not so active during their swimming in winter compared with in summer. This phenomenon was also confirmed by visual observation during the research done. In comparing with the other species it is reported that yellowtail were normally not active enough in water temperature of $13.5^{\circ} \mathrm{C}^{2)}$

\section{Comparing of Hydrophone Position}

The curve pattern of big-sized fish sound in winter during swimming with hydrophone dipped $6 \mathrm{~m}$ inside net pen and $6 \mathrm{~m}$ outside net pen showed the same level and pattern (Fig. 10). Overall, underwater sound of big-sized fish during swimming activity was $111.1 \mathrm{~dB}$ when hydrophone was dipped inside the net pen and was $110.7 \mathrm{~dB}$ when the hydrophone was dipped outside the net pen.

The curve pattern of big-sized fish in winter during baiteating with the hydrophone dipped $2 \mathrm{~m}$ inside the net pen and $2 \mathrm{~m}$ outside the net pen showed same pattern (Fig. 11). The sound level of the curve pattern with the hydrophone dipped $2 \mathrm{~m}$ inside was higher than with the hydrophone dipped $2 \mathrm{~m}$ outside the net pen at all frequencies. The difference in sound levels of both curves was high in low frequency and diminished when the frequencies become high. It is presumed that fish movement was very active under bait-eating in comparison with swimming activity. This phenomenon also was confirmed by visual observation during the research done.

According to Hawkins, ${ }^{7)}$ hydrodynamic sounds are produced by fish that are actively swimming, or rapidly turning. Though much of the disturbance recorded on a hydrophone in the vicinity is generated by water turbulence, a 
booming or rushing sound is often detectable at several meters.

The overall underwater sound of big size specimens during bait-eating activity was $120.4 \mathrm{~dB}$ when the hydrophone was dipped inside and was $108.5 \mathrm{~dB}$ when the hydrophone was dipped outside the net pen.

In conclusion, (1) The small and big-sized fish show the same curve patterns during swimming and bait-eating activity in summer; (2) The bait-eating sounds of Japanese horse mackerel in summer showed the same pattern in both of small and big sized fish. The bait-eating sound of big-sized fish in winter showed a flat pattern, but in summer it showed a curved pattern. The bait-eating sound of big-sized fish in winter showed a flat pattern, but in summer showed a curved pattern; (3) The sound curve pattern of small and big-sized fish in summer showed same pattern during swimming as during bait-eating activities, but the big-sized fish in winter showed a different pattern for both activities; (4) The difference in level of both activities of big-sized fish sound in winter was larger than big-sized ones sound in summer. It is presumed that fishes are not so active during their swimming in winter compared with in summer; (5) The curve pattern of big-sized fish sound in winter during swimming and bait-eating activities with the hydrophone hanging inside and outside the net pen showed same pattern.

Acknowledgments We wish to express our gratitude to the "Fishermen's Production Association', especially Mr. Masato Kawazoe and
Mr. Isamu Kawazoe for kindly providing the experimental fish.

\section{References}

1) T. Hashimoto and Y. Maniwa: Frequency analysis of Marine Sounds, in "Modern Fishing Gear of the World 2" (ed. by $\mathrm{H}$. Kristjonson), Fishing News (Books) Ltd., London, 1964, pp. $410-$ 412.

2) T. Hashimoto and $Y$. Maniwa: Research on the Luring of Fish Schools by Underwatersound, in "Modern Fishing Gear of the World 3" (ed. by H. Kristjonson), Fishing News (Books) Ltd., London, 1971, pp. 501-503.

3) S. Fujieda, Y. Matsuno, Y. Yamanaka, Y.-J. Chung, and C. Kishimoto: Feature of the swimming sound for fishes in the netting cages at the culture ground. Mem. Fac. Fish. Kagoshima Univ., 42, $1-9$ (1993).

4) Y. Matsuno, S. Fujieda, Y.-J. Chun, and Y. Yamanaka: Underwater sound in the net pen at the culture grounds in the innermost area of Kagoshima Bay. Suisan Kaiyou Kenkyuu, 58, 11-20 (1994).

5) Y. Matsuno, S. Fujieda, Y. Yamanaka, F. E. Kaparang, Y. Arita, and T. Kurihara: Underwater sound production by amberjack, (Seriola dumerili), in the net pen at the culture gounds in Sakurajima strait of Kagoshima Bay. Suisan Kaiyou Kenkyuu, 60, 122-129 (1996).

6) F. E. Kaparang, Y. Matsuno, Y. Yamanaka, and S. Fujieda: Studies on underwater sounds produced by yellowtail Seriola quinqueradiata and amberjak Seriola dumerili in net pens at culture grounds in middle kagoshima bay. Fisheries Sci., 64, 353-358 (1998).

7) A. D. Hawkins: Underwater sound and fish behaviour, in "Behaviour of Teleost Fishes" editor T. J. Pitcher. Chapman \& Hall. 2nd ed., Tokyo, pp. 129-169. 